\title{
SISTEMA DE TALLERES PARA APORTAR A LA PREPARACIÓN DE DOCENTES DE EDUCACIÓN ARTÍSTICA, LA IMPLEMENTACIÓN DEL ENFOQUE DE GÉNERO ${ }^{1}$
}

Oriana Martínez Sierra

Resumen: En la sociedad actual, con frecuencia se escuchan reclamos de equidad, lo que hace de esta un reto ante el cual la educación se encuentra en el deber de tomar parte activa en aras de su solución. Las potencialidades de la Educación artística son aprovechadas para que como área tenga la posibilidad de aportar a la solución de dicho reclamo. En tal sentido, se presenta un sistema de talleres que contribuyan a la preparación de docentes de Educación artística, que se desempeñan en el nivel de básica secundaria del municipio La Estrella-Antioquia en Colombia para la implementación del enfoque de género.

Palabras clave: Educación artística, equidad de género

WORKSHOPS SYSTEM INTENDED FOR THE TRAINING OF TEACHERS IN ART EDUCATION APPLYING A GENDER APPROACH.

\section{Abstract}

Claims for equality are currently heard, rising a challenge for education which in its turn must assume an active role if it is to find solutions for this issue. Therefore, the possibilities of Art Education as an area may well be developed in order solve the matter. It is considering this that a system of workshops is herein presented, as they may play a substantial role in the training of Art Education teachers of secondary school in La Estrella, Antioquia, Colombia. So prepared, the teachers may implement a rightful perspective for this genre approach.

\section{Key words: Arts Education, genre equality.}

El presente texto retoma la idea expuesta por la autora en el $V$ Taller internacional Humanísticas 2015, "La enseñanza de las disciplinas humanísticas" en la provincia de Matanzas, Cuba, así como en trabajos personales que viene desarrollando en su recorrido profesional y académico. 


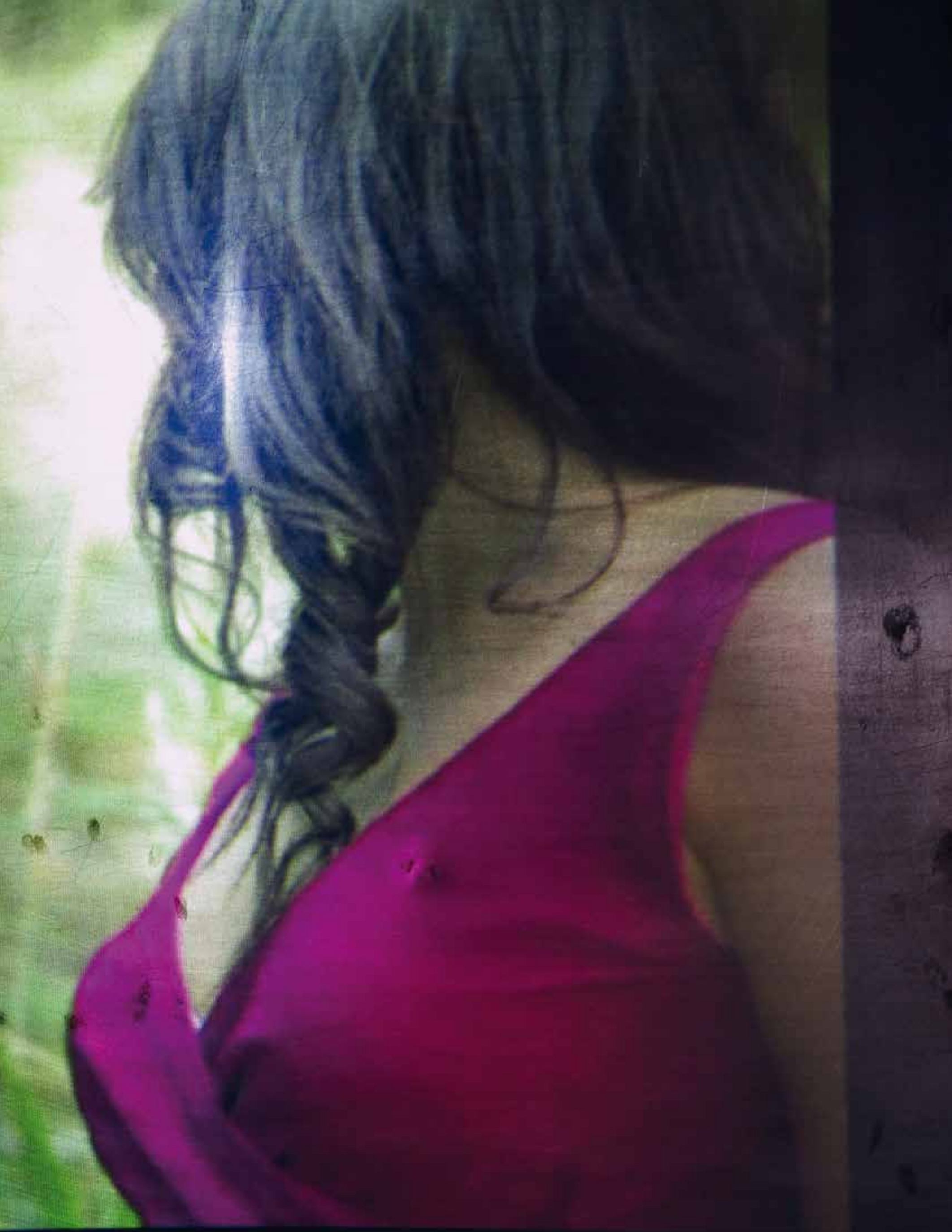




\section{Sistema de oficinas para aportar à formação de docentes de educação artística para a implementação da abordagem de gênero.}

\section{Resumo}

$\mathrm{Na}$ sociedade atual, com frequência escutamse reclamações de equidade, o que faz deste um desafio ante o qual a educação encontra-se na obrigação de tomar parte ativa em beneficio da solução. As potencialidades da Educação artística são aproveitadas, como área, para aportar à solução desta cobrança. Neste sentido, se apresenta um sistema de oficinas que tenta contribuir à formação de docentes em Educação Artística que se desenvolvem no nível de primeiro grau de ensino básico do município La EstrellaAntioquia na Colômbia para a implementação da perspectiva de gênero.

Palavras chave: Educação Artística, equidade de gênero.
Atendiendo a un llamado de cierta colectividad y por interés

personal de quien les escribe, el presente texto tiene como objetivo principal compartir un sistema de talleres, resultado de la tesis de maestría, el cual fue diseñado para aportar a docentes que se desempeñan en el área de Educación artística, específicamente en el municipio de La Estrella, Antioquia, en aras de aportar a la reducción de la presente y lesiva inequidad y el sexismo vigentes en nuestra sociedad. Problemas promovidos por diferentes instancias sociales, dentro de las cuales por omisión se encuentra la escuela, por ello se propone la Educación artística desde sus prácticas extensivas, como un medio idóneo para tal fin. Devenidos de una cultura patriarcal, en muchos de los pueblos del continente americano se está arraigado a asumir posiciones que desde temprana edad generan fuertes diferencias entre macho - hombres y hembra - mujeres con lo cual se da una perpetuación de la inequidad y por tanto de una sociedad sexista. Constituye, por ende, un reclamo en el contexto social colombiano, una mirada aguda a la situación que se presenta en la contemporaneidad, determinada por las relaciones que se establecen entre los ciudadanos a partir del sexo que representan. Desde el Ministerio de Educación Nacional de Colombia (MEN) se expresa el interés por asumir el reto que constituye para la educación general garantizar en la ciudadanía colombiana una formación integral, esto se manifiesta en el contenido de diversos documentos expedidos por esta instancia tales como: los Lineamientos Curriculares, el Plan Nacional de Educación 2006-2016, cartillas que llevan por nombre En ruta hacia la equidad, entre otros.. En tal sentido, desde el Plan Nacional para la Educación artística (PNDE, 2007), se asevera que el progreso de la condición humana se encuentra sujeto a que se promueva un nuevo tipo de ser humano consciente y capaz de ejercer el derecho al desarrollo justo y equitativo, que interactúe en convivencia con sus semejantes y con el mundo, de igual manera se debe promover la participación activa en la preservación de recursos culturales y naturales. Ello apunta a forjar mejores seres humanos -una ciudadanía instruida, conocedora de sus deberes y derechos para con la sociedad-, así como mejorar su calidad de participantes activos en el progreso social, todo esto desde una perspectiva de atención y comprensión de la diversidad. Como seres sociales que somos por naturaleza, establecemos permanentemente procesos de socialización, tanto en la escuela como en las relaciones diarias, lo que permite fortalecernos como tales (Echavarría, 2010); de igual manera se debería contar con la preparación que nos potencialice la capacidad de cuestionar asuntos circundantes en nuestra sociedad como lo son los roles sexistas -estereotipos que en esta se han establecido y que nos son asignados en cuanto nacemos con uno $\mathrm{u}$ otro sexo. $\mathrm{La}$ 
socialización es un proceso mediante el cual se introduce al ser humano en la cultura a través de la enseñanza y aprendizaje de costumbres y normas aceptadas por la sociedad (Echavarría, 2010).

La influencia de la educación familiar y social en los individuos se ha constituido en estereotipos de género que hacen que la mujer y el hombre tengan diferentes funciones sociales, con la consiguiente asignación de roles, cuyos fundamentos subyacen en el sistema patriarcal en el cual han estado inmersos nuestros imaginarios sociales. Estos encasillan a las personas dentro de unos márgenes culturales, limitando su libre desarrollo y acceso a otros ámbitos de actuación diferentes al que le ha sido determinado culturalmente, por ejemplo, fomentando en los niños mayor control en la expresión de afecto y mayor agresividad; y a las niñas, por el contrario, orientándolas hacia una mayor expresividad de cariño, afecto y una mayor sensibilidad hacia los demás (Fernández, 1998). Este tipo de influencias resultan devastadoras a la hora de pensar en una sociedad en la que se practique la equidad de género.

Es así como, inclusive en los juegos, se generan estímulos diferentes. En los niños se reproducen y perpetúan los ámbitos de supuesto interés masculino,

como carros o juguetes electrónicos, que comúnmente promueven la competitividad, la fuerza y la agresividad; las niñas, por el contrario, se rodean de muñecos que representan personas o animales a los que pueden cuidar o de juguetes relacionados con la esfera doméstica o con la belleza, juguetería que incluso promueve de manera marcadamente inferior la actividad física y por tanto el desarrollo de la motricidad gruesa. En esta época de tecnología y cibernética no se puede negar la existencia de los video juegos, de consolas o en línea, sin embargo, la gran mayoría no están exentos de las temáticas anteriores. En estos también encontramos la violencia, la competencia y la guerra para los hombres y la estética, la belleza y el hogar para las niñas (Lobato, 2009). El sexismo en nuestra cultura se encuentra tan arraigado y naturalizado que aún con los espacios ganados por los diferentes movimientos feministas que se han llevado a cabo a nivel nacional e internacional y por las comunidades

LGBTI (Lesbianas, Gays, Bisexuales, Transgeneristas e Intersexuales) es común escuchar que juzgan de afeminado o machona si se ve a un niño o niña jugando con algo o a algo que no ha sido asignado socialmente a su sexo.

Lo sensible de la situación requiere que cada una de las áreas desde las que se concibe la formación del ciudadano en las instituciones escolares asuma el tema de la equidad de géneros como un problema que a todo educador le atañe. En esta perspectiva uno de los principales deberes de la escuela es tributar a la educación del ser humano y no solo a la instrucción del mismo. A lo largo del tiempo, pedagogos del área de educación en general, y de Educación artística en particular, han expresado la necesidad de un cambio en la educación general, en busca de una que sea más flexible, y permita al estudiantado el desarrollo de habilidades que favorezcan su participación como entes sociales.

El artículo 23 de la ley 115/94, Ley General de Educación en Colombia, reconoce la Educación artística como fundamental y obligatoria en el conocimiento y la formación del estudiantado colombiano, puesto que es creadora de comunidades fluidas y dinámicas que configuran procesos de relación y convivencia; además, propicia la creación de espacios para el diálogo 
evidenciando el papel de la diversidad cultural que moviliza y enriquece las identidades, particularmente, por su carácter humanista y, por tanto, reflexivo.

Desde los Lineamientos Curriculares se reconocen en el área de Educación artística potencialidades para formar al estudiante para la vida laboral y en sociedad, adquiriendo en el proceso de enseñanza y aprendizaje habilidades, como análisis, juicio crítico y pensamiento holístico. En tanto el arte, propone potenciar talentos existentes en estudiantes. Se puede afirmar, entonces, que la educación general en Colombia, a la cual la Educación artística tributa, apunta a la formación de seres humanos que aporten al desarrollo de una comunidad íntegra y en armonía, donde la sana convivencia sea protagonista. Armonía a la cual se podría aportar con mayor potencia si la Educación artística fuese impartida con un enfoque de género que apoye la equidad y las prácticas no sexistas.

Constituyen estos, aspectos a tener en cuenta para entender por qué se propone la Educación artística como área que aporta al tratamiento de temáticas tan sensibles como la equidad de género o el respeto a la diversidad de sexo, todo

lo cual se engloba en lo que desde la política educativa a nivel internacional se identifica como asumir procesos con un enfoque de género. En tal sentido, a la Educación artística se le atribuye gran responsabilidad asociada principalmente con la intencionalidad estética con que se abordan los temas y con ello las obras de arte que serán llevadas al aula de clase, sin importar a qué lenguaje artístico correspondan. Es decir, desde el punto de vista de la autora, se consideran como favorables los espacios desde los que el contacto con el hecho artístico propicia la reflexión sobre determinadas temáticas. En todo ello se hace necesario insistir en el valor comunicativo del arte.

Un aspecto que marca la diferencia en todo empeño por realizar tal propósito lo constituye tener en cuenta el nivel por el cual transite el estudiante con que se lleve a cabo el proceso educativo $\mathrm{y}$, en correspondencia, las herramientas pedagógicas con que cuenta cada docente para emprender tan ardua tarea. Ello le imprime un sello particular al trabajo pues cada nivel educacional se distingue por determinadas características. Si bien, sensible y necesario resulta en cualquier contexto abordar esta temática, en el trabajo con adolescentes -por lo que representa el tránsito por ese período del desarrollo en una persona- se requiere de profesionales de la educación con una adecuada preparación para enfrentarla. Punto este que cuenta en contra de un adecuado proceso en la Educación artística, ya que esta es una de las grandes falencias presente en el contexto educativo colombiano en general. Respecto a la adecuada preparación del cuerpo docente, el área de Educación artística presenta una situación algo atípica e incluso agravada, puesto que los programas de formación de los que egresan las y los docentes que afrontan el proceso de enseñanza y aprendizaje del área exhiben una gama bastante amplia. Dentro del cuerpo docente que se desempeña en el área de Educación artística, principalmente en el sector público, hay profesionales cuya preparación puede corresponder a una de las expresiones artísticas en específico, a un programa de licenciatura en artes, así como a cualquier programa académico superior. Se encuentran en desempeño práctico docentes cuya preparación responde a la licenciatura en Educación especial, traducción inglés/francés-español, ingenierías, entre otras profesiones.

Se requiere, por ende, de una sólida preparación del docente en lo correspondiente al área de Educación artística y al tratamiento que implica asumir el referido proceso con enfoque de género. Lo anterior demanda de una mirada crítico constructiva a la educación, así como la resignificación de los aprendizajes en las instituciones escolares. Ello precisa tener en cuenta las potencialidades de la Educación artística como área sensible para aportar

a la mitigación de una de las problemáticas que se presenta en el contexto social y educativo en Colombia: la necesidad de una Educación artística con enfoque de género.

Estudios realizados por representantes de la pedagogía en Educación artística a nivel internacional como Barbosa (1990), Efland (2004), Pimentel (2008), Agirre (2005), Kerr Junior (2008) y Acaso (2011) -profesionales interesados en la relación entre el arte, la educación, la educación artística, el desarrollo de la personalidad y la necesidad de contribuir a una sociedad más equitativa-,

constituyen referentes importantes para la presente tesis, en tanto precisan las potencialidades del área de

Educación artística en función de las exigencias de asumir el proceso educativo con enfoque de género. No obstante los valores reconocidos en los referidos estudios, constituyen aspectos menos logrados aquellos relacionados con las particularidades de este trabajo, a partir de las demandas de un nivel educacional en particular.

Los intercambios académicos y científicos con profesionales colombianos del área de Educación artística, el análisis de los resultados de monografías 


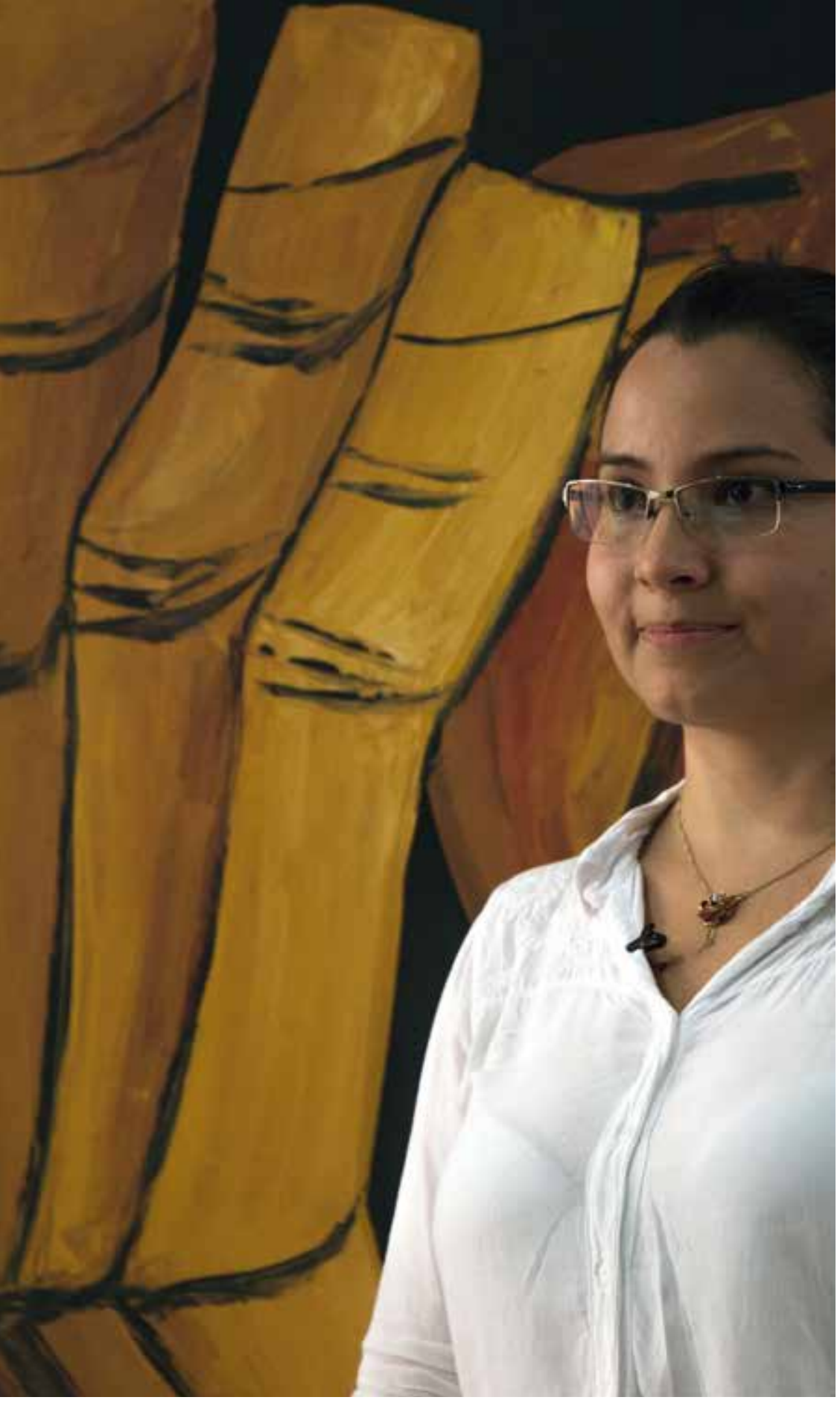

y tesis de grado elaboradas por estudiantes y docentes de la Facultad de Artes de la Universidad de Antioquia, Colombia, así como, la experiencia de la autora -desde su desempeño práctico como docente en el área de Educación artística en el nivel de básica secundaria en el municipio La Estrella-Antioquia en Colombia-, permiten reconocer que aun cuando el enfoque de género está planteado como eje transversal del currículo escolar y se han publicado documentos por parte del MEN que reclaman la implementación de dicho enfoque, no siempre se alcanzan las aspiraciones en la práctica educativa escolar. Tal afirmación, centrada en el área de Educación artística, permite identificar las siguientes insuficiencias:

Los diferentes programas de formación de los que proceden los docentes que se desempeñan en el área de Educación artística hacen evidente las carencias de la preparación profesional correspondiente a la asignatura. Existe, entre los docentes, gran cantidad de mitos y prejuicios en relación con la equidad de género en la sociedad colombiana, los cuales influyen en la posición que estos asumen al pretender abordar

la temática en el contexto educativo. El cuerpo docente presenta insuficiencias al asumir con enfoque de género el proceso de enseñanza aprendizaje (PEA), fundamentalmente por limitaciones en el conocimiento relacionado con dicho enfoque. En los documentos normativos del área de Educación artística no se precisan con suficiencia los elementos

de la concepción del enfoque de género. En la preparación del personal docente no han sido tratados suficientemente aspectos teóricos y metodológicos que permitan la implementación del enfoque.

Lo expuesto con anterioridad hace evidente una contradicción. Esta se materializa en el hecho de que, aun cuando se identifica en los documentos normativos del MEN y en el currículo escolar como eje transversal el enfoque de género, sumado al hecho de que áreas como la Educación artística son factibles para dar tratamiento a este tema, el cuerpo de docentes de la referida área no cuenta con una preparación que le permita implementar el enfoque a partir de tal demanda.

Como se hizo mención al inicio y teniendo en cuenta el panorama expuesto, la autora propone un sistema de talleres para contribuir a la solución de dicho reclamo, no obstante y teniendo en cuenta una de las insuficiencias detectadas, es necesario para la comprensión y para tener una misma mirada dentro de la interpretación del presente texto, aclarar de manera concreta algunos conceptos que se han y continuarán siendo empleados dentro del texto como: sexo, género y equidad de género.

Las definiciones expuestas por autoras como: Garrido J, (2001), Marqueira (2001), Echavarría, M (2010), González H, y Castellanos S, (s/f), entre otros, son 
las que la autora del presente texto asume como conceptos debido

a las coincidencias, y en ese sentido las ha empleado en la presente propuesta.

Sexo: hace referencia a los aspectos anatómicos del ser humano asociados a los genitales desde los que se diferencian machos (masculino) y hembras (femenino).

Género: es un concepto que alude a los significados dados, atribuidos y esperados por cada sociedad, en los aspectos ideológico y de comportamiento para cada uno de los sexos; lo cual incluye las actitudes, valores y expectativas sobre las formas "adecuadas" de ser hombre y de ser mujer en un contexto determinado. Cuando aludimos al género como una categoría para el análisis de la realidad social, cultural e histórica, nos estamos refiriendo a una imagen intelectual, a un modo de considerar y estudiar a las personas, a una herramienta analítica que nos ayuda a analizar la sociedad desde una perspectiva ignorada. Es una forma conceptual de análisis socio-cultural que desafía la ceguera que los estudios sociales han demostrado respecto del sexo. Es una categoría específica del contexto, depende de él y como tal tiene que ser concebido.

Se hace referencia a enfoque de género, porque desde la posición de la autora es imposible lograr oportunidades, derechos, beneficios de un género, si no se transforman simultáneamente las del otro. Por tanto, se habla de equilibrio, de beneficios mutuos, de respeto y de diversidad, diferente postura a una igualdad, ya que en la equidad se busca hacer conciencia de las virtudes, que pudiese llegar a tener un cuerpo y las consecuencias que estas traen consigo, como es el hecho de la maternidad.

El proceso de sistematización de fundamentos teóricos que sustentan la preparación de docentes en el área de Educación artística del nivel de básica secundaria para la implementación del enfoque de género ha llevado a la autora a precisar que un docente de educación artística, para el contexto colombiano, debe cumplir con: conocimientos correspondientes a la asignatura así como del enfoque de género; relacionarse y relacionar al estudiantado constantemente con las diferentes expresiones artísticas del contexto; estar en constante actualización tanto de los contenidos del área, como de las necesidades sociales del contexto al que corresponde; por último, debe ser consciente de los aportes que puede hacer la educación artística, para una sociedad más sana.

Con base en esto, diseña el siguiente sistema de talleres cuyo objetivo general es "Contribuir a la preparación de docentes que se desempeñan en el área de Educación artística y cultural en el municipio de La Estrella-Antioquia, en Colombia, para la implementación del enfoque de género". Este sistema se sustenta en los siguientes 5 fundamentos: Vías para la preparación de docentes en el contexto colombiano. Precisiones del Sistema Educativo en

Colombia en general y aquellos asociados al enfoque de género en particular. Conceptos asociados al enfoque de género. Contenido de los documentos que rigen el proceso educativo del área de la Educación artística. Las exigencias del trabajo en el área de Educación artística por competencias: sensibilidad, apreciación y creación.

Está estructurado por 11 talleres. Cada uno consta de: Título, objetivo, procedimientos por momentos (introducción, desarrollo y cierre) y bibliografía.

Cada taller se desarrolla teniendo en cuenta que en:

- la introducción se debe presentar el tema del taller y el objetivo; llevar a la conformación de equipos de trabajo así como la entrega del material de apoyo.

- el desarrollo de los talleres se procederá a la reflexión e intercambio de criterios que promuevan la construcción de conocimientos y toma de decisiones.

- el cierre de cada taller se precisará la exposición de conclusiones. Será este el momento oportuno para que desde la socialización del tema del próximo taller se enfatice en los aspectos que requerirán de la autopreparación de quienes participan. De igual manera, en este momento se recogerán las valoraciones de los participantes respecto a lo acontecido en el taller.

En el caso específico de la metodología a emplear, en cada taller se sugiere la activa y participativa por lo que propicia con respecto a la dinámica del mismo. En el caso de la evaluación, esta adquiere un carácter sistemático atendiendo al nivel de participación de los talleristas en la discusión sobre aspectos concernientes al tema del taller, haciendo corresponder los aspectos fundamentales desde su tratamiento teórico y su experiencia práctica, la elaboración de conclusiones por grupos y la exposición en plenaria.

Dado el seguimiento que amerita la puesta en práctica del sistema de talleres propuesto a consideración de la autora de la presente investigación, se sugiere en el contexto de la evaluación de cada taller aplicar la técnica matriz FODA para controlar las fortalezas, oportunidades, debilidades y amenazas.

A continuación, se presentan los talleres que se integran en el sistema: 


\section{Taller \#1}

Título: La Educación artística en el contexto educativo colombiano; una mirada desde los documentos normativos

Objetivo: Valorar la importancia de la educación artística en el contexto educativo colombiano desde el contenido de los documentos normativos.

Procedimientos: Introducción

En grupos darán respuesta a la pregunta: ¿qué importancia le concede usted a la Educación artística? Posteriormente se socializa y se llega a una idea central. Al finalizar las exposiciones, se debe leer los fragmentos extraídos de documentos normativos en los que se haga referencia a este particular (importancia de la Educación artística)

Para el cierre, se precisarán los aspectos de relevancia expuestos en los documentos del MEN, desde los que se sugiere la implementación del enfoque de género como eje transversal en el contexto del PEA de la Educación artística, así como las competencias a las cuales se debe tributar desde la referida área.

\section{Taller \#2}

Título: Un llamado a la implementación del enfoque de género desde la Educación artística

Objetivo: Reconocer la esencia de términos que se asocian al enfoque de género ante el reclamo de su implementación en el contexto de la Educación artística.

Procedimientos: se retomará la idea conclusiva del taller anterior, en el que se precisó que la implementación del enfoque de género se reconoce como eje transversal en área de Educación artística. En equipos deberán definir los conceptos: género, equidad, sexo, sexualidad, roles sociales, sexismo, enfoque de género. A continuación, deberán realizar una ilustración de cada concepto. Se procederá al análisis del contenido de las ilustraciones en las que se valorará a partir del empleo de los colores y, posiciones en los diferentes planos, el criterio a partir del que establecieron la relación entre la definición expuesta con anterioridad y su representación visual. Constituirá este momento el pretexto para reflexionar en torno a las virtudes del arte como medio de expresión y comunicación, así como al arraigo sexista que se hace evidente en el tratamiento espontáneo al enfoque de género, lo que denota la naturalización del machismo como tendencia en las culturas patriarcales; esto exige una mirada en el contexto colombiano del siglo XXI. Para el cierre: quien dirige el taller enfatiza en los conceptos que se trabajaron y precisa que las cartillas "En ruta hacia la equidad de género", textos elaborados y emitidos por la gobernación de Antioquia, constituyen la fuente de la cual fueron extraídas estas definiciones.

\section{Taller \#3}

Título: Acercamiento a la implementación del enfoque de género desde la Educación artística

Objetivo: Extraer y valorar de los documentos ideas que sustenten la relación entre Educación artística y la implementación del enfoque de género.

Procedimientos: ara presentar el tema del taller se inicia con la siguiente afirmación:

"Históricamente ha tenido la Educación artística relación con el enfoque de género."

A partir de esta, las y los talleristas discutirán sobre la relación, teniendo en cuenta el cómo y desde cuándo consideran fue establecida. Quien dirige el taller realiza una exposición de momentos relevantes en la historia de la Educación artística en Colombia, resaltando que el sexo siempre tuvo un papel importante en tanto, desde esta área a las mujeres les enseñaban prácticas asociadas al tejido y/o modistería en sentido general y a los varones talla en madera, talabartería, entre otros.

La exposición por parte de la persona que dirija el taller alternará con la presentación del interrogante: ¿qué criterios tiene en relación con las oportunidades que históricamente han tenido hombres y mujeres ante la posibilidad de participar como creadores, intérpretes o simple consumidores de cualquiera de las expresiones artísticas a partir de su diversidad de lenguajes artísticos?

Promover el debate llevará a la precisión de otros aspectos que justifiquen la relación entre la Educación artística y el enfoque de género. Por ejemplo, desde la exposición de criterios o posiciones que revelen el carácter sexista al inicio de esta relación atendiendo sobre todo al tratamiento como objeto y no como sujeto de la mujer en el arte, así como a los atropellos a los que eran sometidos los hombres. Todo ello propiciará que se reflexione en torno al reclamo de que Educación artística y enfoque de género se conjuguen en una visión que promueva la equidad.

El debate será apoyado por la presentación de obras de arte que evidencien la condición de la mujer como objeto y sujeto, discutiendo sobre las diferentes características iconográficas y cargas socio políticas de cada obra presentada, también se hará referencia a la castración del hombre, con fines artísticos (musicales).

Cierre

Se concluye el taller tomando decisiones relacionadas con la contribución que como docentes del área Educación artística se puede hacer en aras de aportar al cambio de relaciones inequitativas y sexistas, persistentes en algunas aulas de clase, por relaciones de equidad y no sexistas. 


\section{Taller \# 4}

Título: Educación artística, responsabilidad y el enfoque de género

Objetivo: Extraer y valorar de los documentos que rigen la Educación artística, emitidos desde el MEN, en dónde se solicita la implementación del enfoque de género desde la dirección del PEA.

Procedimientos: se hace entrega de un papel con un número y un fragmento de los documentos del MEN a cada persona del grupo. Los fragmentos contienen citas de legislaciones nacionales e internacionales, firma de tratados en las que se referencie la importancia, posibilidades y responsabilidad que le han sido atribuidas a la Educación artística respecto al aporte para el mejoramiento de la convivencia en sociedad, dentro de los cuales se encuentra la equidad de género. Algunos de los fragmentos a entregar pertenecen a:

\section{- La Ley 115 de 1994 o Ley General de Educación}

- La Ley 823 de 2003 o Ley de Igualdad de Oportunidades para las Mujeres - El Plan Decenal de Educación 2006-2016 que plantea dentro de sus propósitos: El sistema educativo debe garantizar el respeto a la diversidad de etnia, género, opción sexual, discapacidad, excepcionalidad, edad, credo...

- $\quad$ Ley Orgánica 1151 de 2007

Las personas se buscarán según el contenido de cada papel entregado, para conformar un equipo. Cada equipo debe construir una puesta en escena en la que representen el fragmento asignado. Para el cierre, la persona que dirige el taller lee nuevamente las citas y propone un debate final a través de las siguientes preguntas: ¿En qué medida se le puede dar tratamiento a los aspectos referidos anteriormente desde el PEA? ¿En qué momento o de qué manera desde la concepción del PEA se puede implementar el enfoque de género u otros aspectos de carácter sociocultural?

\section{Taller \#5}

Título: "La imagen que proyectamos"

Objetivo: Revelar la naturalización del sexismo en la sociedad colombiana.

\section{Procedimientos:}

Conforman equipos. Se les hace entrega de materiales, dentro de los cuales se encuentra una imagen en blanco y negro en la que se representa una acción. Apoyándose en la imagen deberán construir una historieta, y esta misma debe estar incluida como una escena o cuadro de diálogo. Finalizadas estas, se procede a la socialización. En esta oportunidad, quienes guiarán el proceso de análisis será el grupo de talleristas, deben tener en cuenta los aspectos iconográficos vistos con anterioridad. Se trata de ser minucioso con el enfoque de género que cada equipo consciente o inconscientemente propone a través de su historieta. Ello permitirá reflexionar en torno a la importancia que cada elemento cobra en una composición. Para el cierre, se realizará la retroalimentación de la actividad, a partir de las respuestas a los siguientes interrogantes: ¿Qué aprendimos?, ¿de qué nos sirvió?, ¿lo podemos emplear en el aula de clase? ¿Qué particularidad tendrían estos ejercicios al trabajar con estudiantes, atendiendo al nivel de básica secundaria por el que transiten?

\section{Taller \#6}

Título: Equidad de género en y desde el PEA

Objetivo: Reconocer la equidad de género como una problemática social que requiere ser tratada en y desde el PEA de la Educación artística.

Procedimientos: se dispone el grupo en equipos. Por equipos se hace entrega de: hilos de coser de diversos colores, agujas, tijeras, lápices de color y un cuarto de pliego de papel resistente a la costura manual. Se indica pensar en una escena familiar en la cual la equidad de género se encuentre presente. Cada persona diseñará un boceto y discutirán las diferentes escenas en aras de ganar claridad en cuanto a lo que exige referirse a equidad de género. Para la discusión se debe tener en cuenta que hay una tendencia a abordar la equidad de género en los contextos familiares desde el intercambio de roles. Esta tendencia debe ser detectada y criticada. Finalmente, el diseño será cosido en el papel entregado. El cierre se concibe a partir de los acuerdos a los que se llegue desde el siguiente planteamiento: Teniendo en cuenta su desempeño como docentes del área de Educación artística, expongan qué actividades sugieren desarrollar para trabajar la temática de la equidad de género atendiendo a la diversidad de técnicas y materiales que pueden emplearse con estudiantes del nivel de básica. 


\section{Taller \# 7}

Título: Adiós bella durmiente

Objetivo: Valorar críticamente cuentos tradicionales, empleando otras tendencias literarias como paralelo.

Procedimientos: por equipo se hace entrega de una copia de cuentos de la escritora española Adela Turín: "Rosa Caramelo", "Una feliz catástrofe", "Arturo y Clementina", "Los Bonobos con gafas". Cada cuento será rotado después de ser leído. En mesa redonda se socializan las interpretaciones que suscitó la lectura de los cuentos en relación con el tratamiento del enfoque de género desde la literatura infantil tradicional y la literatura infantil a favor de las niñas, también se observan con detalle las ilustraciones de cada cuento. Se convoca a los talleristas a la reflexión a partir del contenido de la guía para el análisis de cuentos infantiles elaborada por la propia Adela Turín, "Los cuentos siguen contando" en la cual se aborda el significado del empleo de algunos símbolos en su literatura. A todo ello le antecederá la pregunta ¿Sabías qué?. Para el cierre: se propone revisar las composiciones realizadas con anterioridad, como el cómic, aplicándole los ítems sugeridos por Adela Turín, y observar qué nuevos resultados se obtienen de esta relectura iconográfica.

\section{Taller \# 8}

Título: Apertura al enfoque de género

Objetivo: Identificar la apertura al enfoque de género desde las diferentes manifestaciones artísticas.

Procedimientos: se pide elaborar un resumen en el que se esbocen los símbolos identificados en el taller anterior "Adiós bella durmiente" y aquellos conceptos asociados al enfoque de género que con anterioridad se abordaron, estos son, sexo, género y equidad. Se procede a la presentación de materiales representativos de las diferentes manifestaciones en los que desde su contenido se visualicen posiciones sexistas: comerciales televisivos, canciones, videos musicales, posters, videos de representaciones dancísticas, fragmentos de puestas en escena, fragmentos de filmes, entre otros productos visuales y audiovisuales. Se sugiere tener en cuenta artistas musicales como: Bebe de España, Gabilonia de Venezuela, Danay Suárez de Cuba, quienes en sus composiciones reclaman condiciones más favorables para el sexo femenino, o las ponen en lugares de equidad respecto al sexo masculino; en contraposición, se sugiere canciones como, Corazones rojos de Los Prisioneros y Mujer Florero de Ella Baila sola, canciones que se destacan por dar un tratamiento altamente machista, incluso peyorativo al sexo femenino.

En la medida en que se avanza, se propicia el debate en torno al tratamiento al género a partir de los roles sexistas. Se ha de enfatizar en los recursos expresivos empleados. Para el cierre, se induce al grupo a concluir que el resultado de todo proceso artístico es material en potencia para tratar el enfoque de género dentro de las aulas de clase.

\section{Taller \# 9}

Título: Imagen que cobra vida

Objetivo: Revelar que el género es una construcción y que esta inicia desde temprana edad.

Procedimientos: por docente se hace la asignación de los siguientes materiales: una hoja con la impresión en blanco y negro de imágenes definidas como balones, zapatos y otros, algunas figuras geométrica y siluetas que sugieran algo, pero que a su vez se preste para varias interpretaciones, por ejemplo, el triángulo que puede sugerir una falda, una capa, algo para llevar en la mano, etc. De igual forma, debe incluir una figura que sugiera, lo más cercanamente posible, desde la forma en negativo, el cuerpo humano; en esta figura no debe ser legible el sexo, pues este será asignado por cada tallerista. Además, se les hará entrega de papel y lápices de color: amarillo, rojo, azul, verde, rosado, violeta. Quienes participan en este taller deberán hacer uso únicamente de los 6 colores entregados por quien dirige el taller; no crearán colores secundarios.

Con los elementos anteriormente entregados deben crear un personaje con su correspondiente historia y luego, en equipos, construir una historia en la que se incluyan todos los personajes, respetando las características asignadas desde el inicio. Para el cierre se enfatiza en el género como asignación social que en ocasiones dificulta y condiciona el desarrollo de la libre personalidad de cada ser humano.

\section{Taller \# 10}

Título: Reinterpretaciones

Objetivo: Reconocer el tratamiento dado al enfoque de género y el sexismo en el arte.

Procedimientos: se debe contar con una presentación previamente diseñada, en la que se exponga obras de arte visuales, de igual manera debe contar con la impresión de cada una de ellas y material para elaborar la reinterpretación, cada obra contará con un breve análisis. La mirada con enfoque de género debe ser cada vez más hábil y minuciosa por parte del grupo participante. Para el ejercicio de reinterpretación, deben cambiar los aspectos sexistas identificados en la obra, empleando como apoyo los símbolos y conceptos tratados en talleres anteriores. Para el cierre se exponen las dos obras, la "original" y la propuesta por cada docente justificando los cambios realizados. Se establecerá un intercambio desde el que compartan dichos cambios y el resto de grupo valorará si la intención se cumple o no. 


\section{Taller \# 11}

Título: El género y los juguetes

Objetivo: Planificar actividades en las que esté presente de manera explícita el enfoque de género.

Procedimientos se entregará un resumen de los conceptos tratados en los talleres anteriores, las propuestas artísticas, conclusiones y las competencias con las que debe cumplir (específicas) y a las que debe tributar (básicas), expuestas en los documentos emitidos por el MEN. Apoyándose en este se pide a los docentes construir actividades que puedan ser desarrolladas con sus propios estudiantes.

En mesa redonda se propone compartir, ampliar o mejorar, de ser necesario, las propuestas que de manera individual fueron creadas. Para el cierre se entrega a cada participante una impresión con el texto de "El experimento de los monos y los plátanos”, este será leído en voz alta. Además, se proponen las siguientes preguntas: Piensa en los juguetes y juegos de cuando eras infante.. piénsalo con sinceridad... ¿regalarías a tu hermano u otro niño una muñeca? ¿Crees que hay juegos solo para niñas o solo para niños? ¿Qué piensas si ves a un niño peinando y acunando una muñeca? Piensa en todas las veces que has dicho o pensado "esa chica es un poco marimacho" o "ese es un afeminado", recuerda que la alteridad existe. Con sinceridad respóndete y piensa las veces que te has autoimpuesto algún limite o has dejado de hacer o decir alguna cosa por lo que "iban a decir o pensar" tu grupo de iguales, por no considerarse propio de tu sexo...

\section{Conclusiones}

Se diseña y propone un sistema de talleres que contribuya a la preparación de docentes del área de Educación artística en el nivel de básica secundaria del municipio La Estrella, Antioquia, para la implementación del enfoque de género. El mismo responde a las particularidades y necesidades actuales del currículo para la educación básica secundaria en Colombia.

En el sistema de talleres propuesto se reconocen como cualidades el ser flexible, contextualizado, participativo y sistémico por lo que, luego de haberse sometido al criterio a especialistas, se evidenciaron aquellos elementos que revelan su factibilidad. Esto permite que sea perfectible y validado con docentes que se desempeñan en el área de Educación artística en el nivel de básica secundaria en el municipio La Estrella, Antioquia.

\section{Referencias Bibliográficas}

Acaso, M. (2011). El aprendizaje de lo inesperado. Barcelona: Paidós.

Agirre, I. (2005). Teorías y prácticas en educación artística. Barcelona: Octaedro.

Asamblea General de las Naciones Unidas. (2000). Declaración del milenio. Nueva York. p. 10.

Barbosa, A. M. (1990). Arte-Educação no Brasil Realidade hoje expectativas futuras. Brasil.

Castañeda, N. \& Henao, L. S. (1999). Estereotipos sexistas en el lenguaje marginal. En: Lingüística y Literatura. № 34/35. Medellín, p 247.

Cobo, R. (1995). Fundamentos del patriarcado moderno. Jean Jacques Rousseau. Madrid: Cátedra. Col. Feminismos.

Constitución Política de Colombia (1991). Artículo 68. Bogotá: Panamericana.

Echavarría, M.I. (2010). Propuesta para la incorporación del enfoque de equidad de género en los proyectos educativos institucionales "PEI" de las instituciones educativas del municipio de Medellín. Secretaria de las mujeres $\mathrm{f} / \mathrm{d}$

Efland, A. D. (2004). La educación en el arte posmoderno. Barcelona: Paidós. Fernández, J. (1988). Nuevas perspectivas en el desarrollo del sexo y del género. Madrid: Pirámide.

Gonzales, A. \& Castellanos, B. (s/f). Sexualidad y géneros. Alternativas para su educación ante los retos del siglo XXI. f/d.

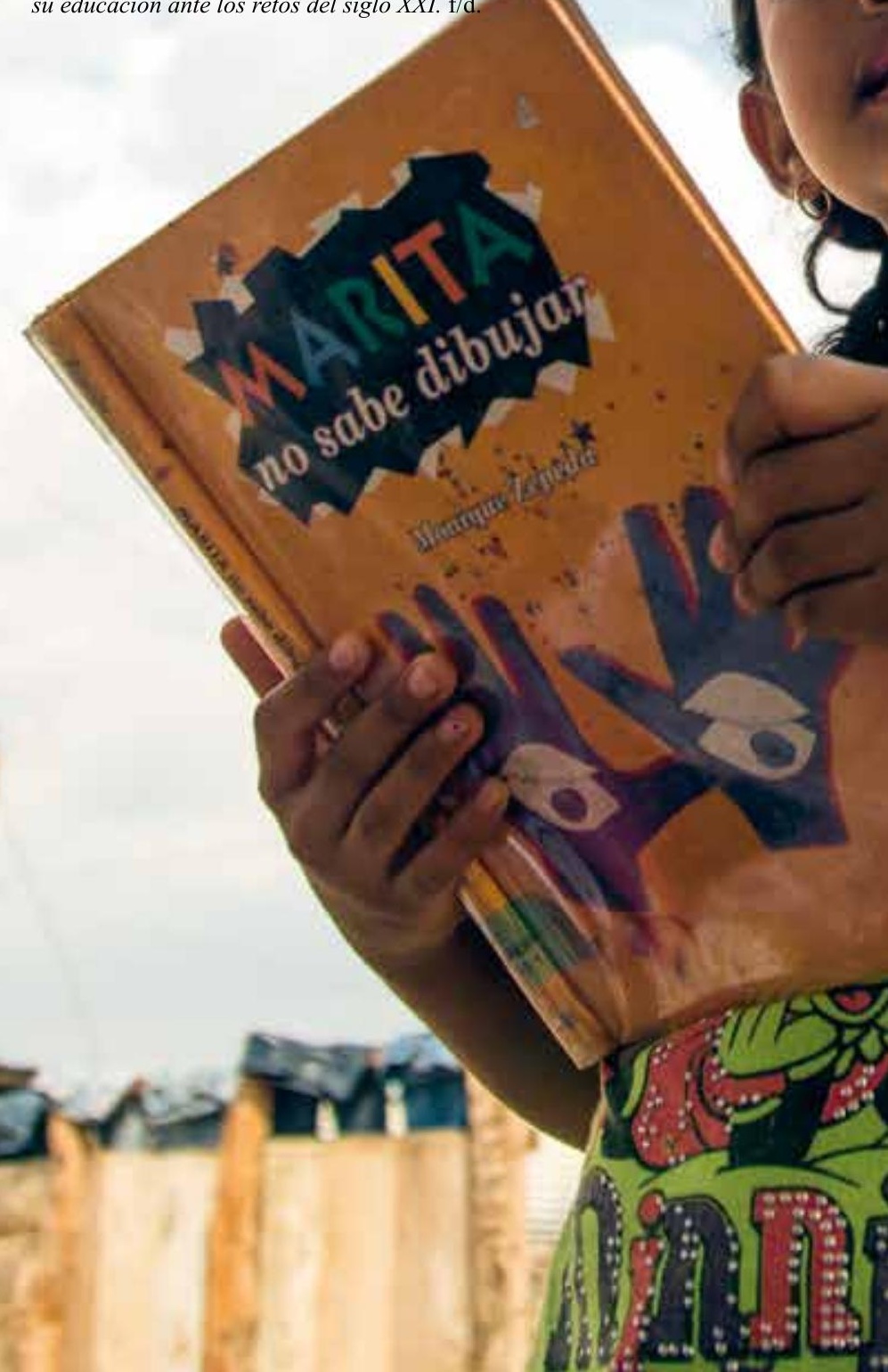


Kerr Junior, D.H.B. (2008). Experiência estética, cinema e ensino de arte. IF Sul-rio-grandense. f/d.

Lobato, E. (2009). Construyendo el género. En Línea. Disponible en: bocarroja.wordpress.com/3-estereotipos-femenino/

María Isabel , E. L. (2010). Propuesta para la incorporación del enfoque de equidad de género en los proyectos educativos "PEI" de instituciones educativas del municipio de Medellín. Medellín, Antioquia: Secretaría de la Mujer. f/d

Ministerio de Educación Nacional. (1994). Ley general de la educación 115 de1994. República de Colombia. En Línea. Disponible en: www. mineducacion.gov.co 1621 article-85906.html

Ministerio de Educación Nacional (1997). Lineamientos Curriculares para la Educación Artística, LIN. Bogotá.

Ministerio de Educación Nacional (2006). El Plan Nacional Decenal de Educación 2006-2016 y los Objetivos de Desarrollo del Milenio,--PNDE. En línea. Disponible en: http://www.plandecenal.edu. co/html/1726/articles-183191_MILENIO.pdf.

Ministerio de Educación Nacional (2007). Orientaciones pedagógicas para la Educación Artística en básica y media, ORPE. Documento $N^{\circ} 15$. Bogotá.

Ministerio de Educación Nacional (2007). Plan Nacional de Educación Artística 2007-2010, PNEA. Colombia: Ministerio de Cultura. www. mineducacion.gov.co
Ministerio de Educación Nacional (2010).

Orientaciones pedagógicas para la Educación Artística en básica y media, ORPE. Documento $N^{\circ}$ 16. Bogotá.

Plan Decenal de Educación 2006 - 2016. Disponible en: www.plandecenal.edu.co

Presidencia de la República de Colombia. Decreto 1278 de junio 19 de 2002. Artículo 38.

Romero, M. del R. (2008). En ruta hacia la equidad de género 2. Medellín: Editorial Universidad de Antioquia. Gobernación de Antioquia.

Varela, N. (2005). Feminismo para principiantes.

Barcelona: Ediciones B, S. A.

\section{Oriana Martínez Sierra}

Magíster en Educación de la Facultada de Ciencias pedagógicas de la Universidad Camilo Cienfuegos de Matanzas Cuba y Licenciada en Educación en Artes Plásticas de la Universidad de Antioquia, integrante del grupo de investigación ARTEDUCACION de la Universidad de Antioquia.

Ori.martinez.s@gmail.com

Artículo recibido el día 4 de octubre y aceptado el 5 de noviembre de 2015 